\title{
Mouth Cancer Action Month
}

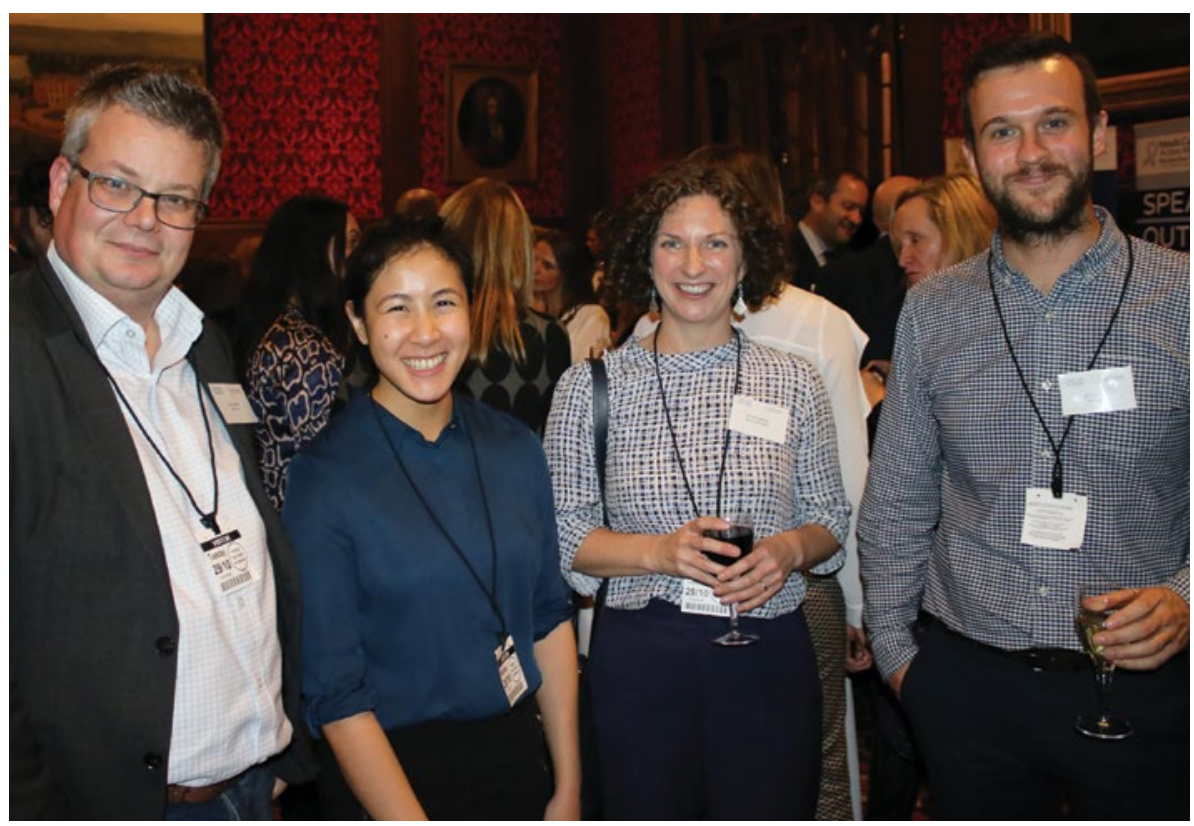

Members of the $B D J$ editorial team mingle at the launch event

\section{Westminster launch}

Mouth Cancer Action Month was launched on 29 October 2019 at the Houses of Parliament. More than 130 people from across 98 organisations joined hosts the Oral Health Foundation and heard from a range of speakers reinforcing the need for greater recognition of mouth cancer and its signs and symptoms.

Dr Carter said: 'The number of mouth cancer cases continues to increase year on year. When we took on this campaign nearly two decades ago, we were looking at just over 3,000 cases each year. In the last year or so, we have had over 8,300 recognised cases of mouth cancer. That is a huge increase, and it is one of the few cancers where the number of cases has started to increase.

'We want everyone to be more mouth aware during this year's campaign. This means being able to identify the signs and symptoms of mouth cancer, understand what is more likely to put us at greater risk, and importantly, know where to go if you spot anything out of the ordinary.

'Early diagnosis saves lives so during November, please help us get across the message "if in doubt, get checked out".

\section{Latest figures}

The Oral Health Foundation's new 'State of Mouth Cancer UK Report 2019/20' shows that 8,337 people in the UK were diagnosed with the disease last year. This has increased by nearly two-thirds (64\%) since 2007 .

New cases of mouth cancer have increased for the tenth year in a row and have more than doubled within the last generation.

The report shows that most mouth cancers are located in the tongue. One-in-three (33\%) mouth cancers are diagnosed in the tongue, while nearly one-in-four $(23 \%)$ are caught in the tonsils. The palate, floor of the mouth, lips and gums are the other common places where mouth cancer occurs.

The research also found that 2,701 people lost their life to mouth cancer last year. That's seven people every day, and survival rates in the UK have barely improved in the last 20 years.

\section{SEND trial}

A new paper published in the British Journal of Cancer says that 30,000 more patients worldwide will be cured if their neck glands are removed at the same time as their small mouth cancer. ${ }^{1}$

The paper describes the first nationwide trial evaluating elective neck dissection for early stage oral cancer.

Commenting on the research, British Association of Oral and Maxillofacial Surgery (BAOMS) Chair Patrick Magennis said: 'This open access paper funded by charity Saving Faces and Cancer Research $\mathrm{UK}$ (CRUK) is ground-breaking. [...]

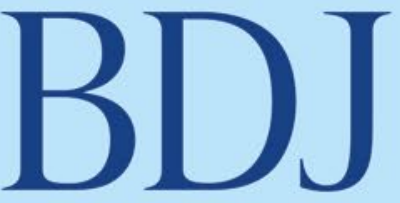

RESEARCH INSIGHTS

\section{FOR ANOTHER VIEW}

- Research insights from across the BDJ Portfolio

- Providing busy readers with valuable context including article summaries and expert commentary

\section{Catch up here:} http://bit.ly/BDJResearchlnsights
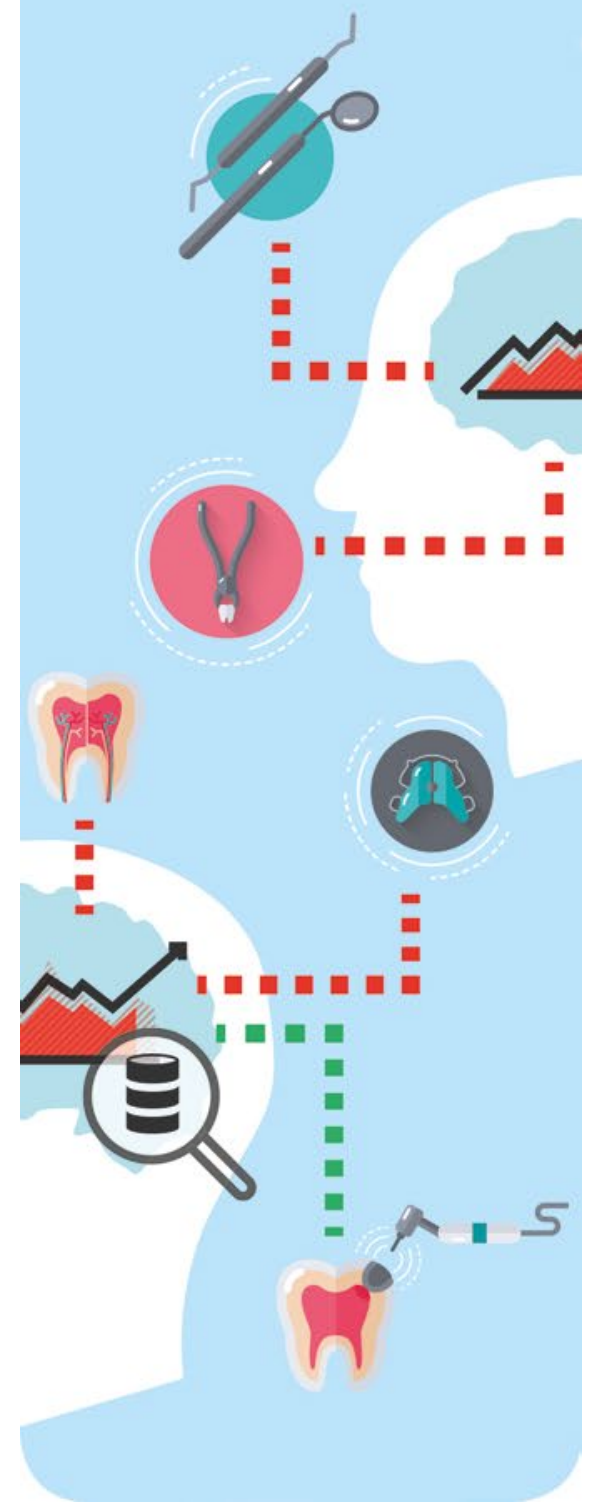
4 The study was possible because of a unique collaboration between 68 UK-based surgeons treating 614 patients at $27 \mathrm{UK}$ hospitals. The research compared leaving or taking out neck glands that did not have obvious secondary cancers at the same time as removing the patient's small mouth cancer. OMFS know that between 20 and 30 in every 100 patients with small mouth cancers have tiny microscopic cancer deposits in their neck glands that can't be picked up by any scanners. Now OMFS have the evidence about the risks and benefits of removing the neck glands in early mouth cancer. This information will help patients participate in decisions about their treatment'

\section{References}

1. Hutchison I L, Ridout F, Cheung S M Y et al. Nationwide randomised trial evaluating elective neck dissection for early stage oral cancer (SEND study) with meta-analysis and concurrent real-world cohort. Br J Cancer 2019; DOI: 10.1038/s41416-019-0587-2. [Epub ahead of print].

\section{DCby1 Practice of the Year Award}

The winner of the NASDAL Dental Check by One

(DCby1) Practice of the Year 2019 Award is Urchfont

Dental Care, Devizes, Wiltshire.

Chief Dental Officer Sara Hurley presented the award to the winning dental team on 18 October 2019 in the Innovation Theatre at the BDIA Dental Showcase at the NEC in Birmingham.

The award is presented every year by NASDAL to recognise the outstanding commitment of practices to the DCbyl campaign. Launched by the British Society of Paediatric Dentistry (BSPD) in partnership with the Office of the Chief Dental Officer, the aim of the campaign is to increase the number of children who access dental care aged $0-2$ years.

Urchfont Dental Care has seen a $17 \%$ increase in new patients aged three and under, and a $33 \%$ increase in new patients aged five and under (20\% of their 139 new patients Jan-Aug this year), compared to the same period in the previous year.

Dr Gwynnifer Henning, Principal of Urchfont Dental Care, said: 'We are so happy to win this award - our entire team work very hard at this and we are passionate about improving the oral health of children. I am sure that winning this award will encourage us to do even more.'

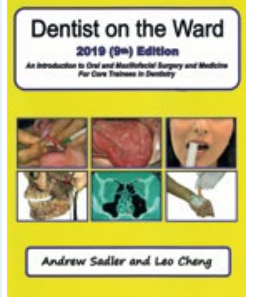

\section{DENTIST ON THE WARD 2019 (9TH EDITION): AN INTRODUCTION TO ORAL AND MAXILLOFACIAL SURGERY AND MEDICINE FOR CORE TRAINEES IN DENTISTRY}

Andrew Sadler and Leo Cheng

Sorejaw; 2019; price $£ 24.50$ pp. 192

ISBN: 9781999361204

Dentist on the ward is an excellent guide for recently qualified dentists preparing for work as a dental core trainee (DCT) within an oral and maxillofacial surgery unit. In this ninth edition, six chapters have been updated to reflect changes in the practice of oral and maxillofacial surgery. This book outlines the professional landscape DCTs will find themselves working in, and their expected roles and responsibilities within the hospital system. Key medical and surgical theory is briefly outlined, however, there is insufficient scope and detail for anyone more advanced within the speciality.

The book has 52 chapters, each approximately three to four pages long. It is divided into four main categories: a practical introduction to the hospital environment; a review of routine procedures expected of a DCT; medical and dental sciences relevant to this role; and a brief introduction to the clinical work of an oral and maxillofacial surgeon. The chapters are easy to read and well illustrated with colour photographs and diagrams.

Where this book excels is in guiding the reader through the tasks expected of a hospitalbased dentist, which otherwise may not be covered in dental undergraduate curriculums or general dental practice. This includes clinical and radiological assessment of a patient with facial trauma, interpreting blood test results and perioperative fluid management. These topics are reviewed briefly, but in enough detail for a DCT or for candidates sitting non-specialist post-graduate examinations.

Information regarding the most common procedures expected of a DCT is underdelivered, such as the chapter on the management of impacted teeth. This could be expanded to include a more comprehensive assessment of extraction difficulty and if or when to escalate to more senior colleagues. Similarly, the chapter on oral biopsies could include more information on biopsy technique and fixation. Overall, there is room for more intraoperative photographs throughout the text, which would assist in bridging surgical theory with practice.

Some major areas of specialist oral and maxillofacial surgery such as head and neck cancer management, orthognathic surgery and management of odontogenic cysts and tumours are introduced. Despite being complex subjects, the information presented in these chapters is brief and well-tailored to the DCT. Expectations of the junior member within the oral and maxillofacial team are well outlined and advice about how best to maximise learning in these contexts is given.

Dentist on the ward is an excellent text for dental students or hospital-based dentists beginning a post in an oral and maxillofacial surgery unit. It provides a good overview of the roles and expectations of a DCT across a range of relevant clinical environments. Information on common clinical procedures is somewhat lacking, therefore this book should be read as a guide with which to supplement the reader's learning and clinical experience. Overall, this text is very relevant and fun to read. We highly recommended it for any dentist about to start their first hospital job.

M. Mian and S. Sreedharan 